\title{
Estimativas de tensão diferencial durante milonitização ao longo da zona de cisalhamento Pernambuco Leste (Província Borborema, nordeste do Brasil)
}

\author{
Raylline Ferreira da SILVA \& Luís Gustavo Ferreira VIEGAS \\ Instituto de Geociências, Universidade de Brasília. Campus Universitário Darcy Ribeiro, Asa Norte, \\ CEP 70910-900, Brasília, DF, Brasil (raylline.silva@outlook.com; lgviegas@unb.br).
}

\begin{abstract}
Resumo. As condições de tensão diferencial ao longo da zona de cisalhamento Pernambuco Leste (ZCPE) foram avaliadas com base na relação piezométrica entre tamanho de grão recristalizado (d) e grau de recristalização dinâmica de agregados recristalizados de quartzo. As bandas miloníticas ricas em quartzo ocorrem tanto no domínio Caruaru quanto no Gravatá, individualizados ao longo da extensão lateral da ZCPE. O domínio Caruaru é constituído por milonitos grossos compostos por agregados recristalizados de quartzo $(\sim 50 \mu \mathrm{m})$ imersos em uma matriz fina de feldspato recristalizado. No domínio Gravatá, há a presença de ultramilonitos com bandas recristalizadas descontínuas ricas em quartzo $(\sim 47 \mu \mathrm{m})$ intercaladas com bandas máficas. As estimativas de tensão diferencial calculadas por piezometria em seis amostras de ambos os domínios são de: i) $30 \mathrm{MPa}(\mathrm{d}=50 \mu \mathrm{m}), 48 \mathrm{MPa}(\mathrm{d}=27 \mu \mathrm{m})$ e $18 \mathrm{MPa}(\mathrm{d}=94$ $\mu \mathrm{m})$ para os milonitos do domínio Caruaru, e ii) $20 \mathrm{MPa}(\mathrm{d}=82 \mu \mathrm{m}), 35 \mathrm{MPa}(\mathrm{d}=40 \mu \mathrm{m})$ e 45 $\mathrm{MPa}(\mathrm{d}=30 \mu \mathrm{m})$ no domínio Gravatá. Os incrementos observados nos valores calculados de tensão diferencial estão associados a partição heterogênea da deformação entre os processos de recristalização dinâmica e mecanismos de fragmentação mecânica e/ou dissoluçãoprecipitação, observados em grãos de quartzo e feldspato, respectivamente. A combinação dos processos rúpteis e dúcteis refletem o caráter reológico transicional da zona de cisalhamento Pernambuco, típico de estruturas exumadas em níveis crustais intermediários a rasos.
\end{abstract}

Palavras-chave. Microestruturas, mecanismos de deformação, transcorrência, Província Borborema, recristalização dinâmica, metamorfismo

\begin{abstract}
EVALUATION OF STRESS CONDITIONS DURING MYLONITIZATION IN THE EAST PERNAMBUCO SHEAR ZONE (BORBOREMA PROVINCE, NORTHEASTERN BRAZIL). Differential stress conditions along the East Pernambuco shear zone (EPSZ) were studied based on the piezometric relationship between recrystallized grain size and dynamic recrystallization rate of recrystallized quartz aggregates. Quartz-rich mylonitic bands occur in both the Caruaru and Gravatá domains, individualized along the lateral extension of the EPSZ. The Caruaru domain consists of coarse mylonites composed of recrystallized quartz aggregates $(\sim 50 \mu \mathrm{m})$ immersed in a fine-grained matrix of recrystallized feldspar. In the Gravatá domain, there is the presence of ultramylonites with quartz-rich recrystallized bands $(\sim 47 \mu \mathrm{m})$ intercalated with mafic bands. The differential stress estimates calculated by piezometry in six samples from both domains are: i) $30 \mathrm{MPa}$ (d $=50 \mu \mathrm{m}), 48 \mathrm{MPa}(\mathrm{d}=27 \mu \mathrm{m})$ and $18 \mathrm{MPa}(\mathrm{d}=94 \mu \mathrm{m})$ for the mylonites of the Caruaru domain, and ii) $20 \mathrm{MPa}(\mathrm{d}=82 \mu \mathrm{m}), 35 \mathrm{MPa}(\mathrm{d}=40 \mu \mathrm{m})$ and $45 \mathrm{MPa}(\mathrm{d}=30 \mu \mathrm{m})$ in the Gravatá domain. The increments observed in the calculated values of differential stress are associated with heterogeneous deformation partition between the processes of dynamic recrystallization and mechanisms of mechanical fragmentation and / or dissolution-precipitation, observed in quartz and feldspar grains, respectively. The combination of brittle and ductile processes reflects the transitional rheological character of the Pernambuco shear zone, typical of structures exhumed in intermediate to shallow crustal levels.
\end{abstract}

Keywords. Microstructures, deformation mechanisms, transcurrent, Borborema Province, dynamic recrystallization, metamorphism. 


\section{Introdução}

Os processos de enfraquecimento reológico associados à nucleação de zonas de cisalhamento envolvem redução do tamanho do grão, enfraquecimento induzido por reações e recristalização dinâmica como mecanismos principais durante localização da deformação (Warren \& Hirth, 2006; Kilian et al., 2011; Platt, 2015). Na escala microscópica, a acomodação da deformação é observada no desenvolvimento de bandas de cisalhamento miloníticas, as quais acomodam processos localizados de redução do tamanho do grão e são, subsequentemente, responsáveis pelo particionamento heterogêneo da deformação durante fluxo viscoso em zonas de cisalhamento (Bukovská et al., 2016; Fossen \& Cavalcante, 2017). A profundidade da deformação e a presença/ausência de fluidos são fatores críticos durante os processos de localização da deformação em diferentes níveis crustais (Fitz Gerald \& Stunitz, 1993; Fliervoet et al., 1997; Fitz Gerald et al., 2006; Handy et al., 2007).

O enfraquecimento reológico induzido por fluidos tem sido amplamente reconhecido como um mecanismo efetivo durante localização da deformação em rochas cisalhadas em níveis crustais intermediários (Wintsch \& Yi, 2002; Menegon et al., 2006). Apesar de comum em exemplos naturais, este processo não é diretamente observado em estudos experimentais, onde agregados de quartzo se comportam como uma fase reológica fraca e localizam a deformação via regimes progressivos de recristalização dinâmica (Hirth \& Tullis, 1992; Tullis, 2002). Os domínios estruturais observados - agregados monofásicos (quartzo) e misturas polifásicas finas (K-feldspato, plagioclásio \pm mica) - resultam de deformação dúctil sob altas taxas de tensão diferencial e coexistem durante fluxo viscoso.

Por outro lado, os mecanismos rúpteis de redução do tamanho do grão - e a subsequente transição para a fluência difusiva - têm sido reportados em sistemas miloníticos polifásicos (e.g. Okudaira et al., 2015; Viegas et al., 2016; Okudaira et al., 2017). Altas taxas de tensão diferencial são responsáveis pelo fraturamento generalizado de objetos rígidos e geração de uma matriz fına que acomoda a deformação a partir de processos de transferência de massa no estado difusivo. Nestes cenários, o enfraquecimento reológico promovido por interações fluido-rocha não é observado e as condições deformacionais são consideradas "anidras" (e.g. Menegon et al., 2011).

A zona de cisalhamento Pernambuco (Nordeste do Brasil) é uma das principais estruturas que compõem o sistema de cisalhamento da Borborema (Vauchez et al., 1995; Van Schmus et al., 2008). A estrutura consiste em cinturões miloníticos que deformam migmatitos e gnaisses de alto-grau na porção oeste (i.e., zona de cisalhamento Pernambuco Oeste, ZCPO; Vauchez \& Egydio-Silva, 1992), enquanto que milonitos recristalizados em graus intermediários a altos nas fácies xistoverde dominam a terminação leste da falha (i.e., zona de cisalhamento Pernambuco Leste, ZCPE; Neves \& Mariano, 1999). Na ZCPE, bandas miloníticas ricas em quartzo ocorrem de forma pervasiva, orientadas paralelamente à foliação milonítica em granitos miloníticos. As relações estruturais entre estas bandas recristalizadas e a trama milonítica registram evidências de localização da deformação em condições rúpteis-dúcteis (Viegas et al., 2016; Castellan et al., 2020), e sugerem que estas estruturas servem como anisotropias planares preferenciais para acomodação da deformação dúctil durante a atividade da ZCPE.

Nesta contribuição, apresentamos um estudo microestrutural quantitativo de bandas miloníticas ricas em quartzo que ocorrem ao longo de toda a extensão da zona de cisalhamento Pernambuco Leste. As bandas de quartzo são deformadas essencialmente por fluxo viscoso, enquanto o restante da rocha acomoda a deformação a partir de fraturamento e dissolução-precipitação em porfiroclastos grossos de feldspato. Com base na investigação de microestruturas, mecanismos de deformação e estimativas de tensão diferencial acumulada em agregados recristalizados de quartzo que ocorrem no interior das bandas recristalizadas, este trabalho tem como objetivo avaliar as intensidades da tensão diferencial associadas à milonitização acomodada ao longo da ZCPE. 
Nossos resultados contribuem para um melhor entendimento do papel da recristalização dinâmica durante deformação rúptil-dúctil ao longo da zona de cisalhamento Pernambuco Leste.

\section{Contexto geológico}

A Província Borborema, localizada no nordeste do Brasil, encontra-se na parte central dos cinturões orogênicos brasilianos-Panafricanos (ca. 650-500 Ma) e está relacionada à formação do continente Gondwana a partir das colisões continentais neoproterozoicas entre os crátons São Francisco-Congo e São Luis-Oeste-Africano (Fig. 1A; Almeida et al., 1981; Van Schmus et al., 1995). A estruturação regional da Província Borborema é dividida em três domínios: Setentrional, Central e Meridional, separados pelas zonas de cisalhamento Patos e Pernambuco (Van Schmus et al., 1995). Trabalhos posteriores sugeriram a compartimentação da Província em cinco domínios geotectônicos: Médio Coreaú, Ceará Central, Rio Grande do Norte, Domínio Central e Domínio Sul, os quais exibem um padrão geométrico conjugado definido por zonas de cisalhamento regionais associadas a um expressivo magmatismo granítico (Fig. 1B; Vauchez et al., 1995; Brito Neves et al., 1999; Brito Neves et al., 2000).

A zona de cisalhamento Pernambuco é uma das principais estruturas tectônicas de escala regional da Província Borborema e pode ser traçada continuamente na direção E-W por mais de 700 km (Neves \& Mariano, 1999). Encontra-se limitada por diversos plútons graníticos e apresenta cinemática destral (Fig. $1 \mathrm{C}$ e D). Dois segmentos principais compõem a zona de cisalhamento Pernambuco, ambos separados pela bacia fanerozoica Tucano-Jatobá (Fig. 1C; Vauchez \& Egydio Silva, 1992): a) um segmento ocidental (Zona de Cisalhamento Pernambuco Oeste, ZCPO) composto por ortognaisses de alto grau, migmatitos e granitoides sincinemáticos, e b) um segmento oriental (Zona de Cisalhamento Pernambuco Leste, ZCPE; Fig. 2A) desenvolvido entre dois batólitos graníticos, em que coexistem cinturões miloníticos descontínuos de alta e baixa temperatura. As foliações e lineações mesoscópicas indicam uma componente dominante de deslizamento paralelo à direção principal da zona de cisalhamento (Davison et al., 1995). Alternativamente, estudos geocronológicos consideram que a zona de cisalhamento Pernambuco representa um segmento crustal homogêneo por toda sua extensão (Santos \& Medeiros, 1999; Brito Neves et al., 2000; Santos et al., 2017).

As porções central e leste da ZCPE são compostas por rochas monzograníticas e granodioríticas com estrutura ortognáissica. A foliação milonítica E-W apresenta mergulho alto e é comumente definida pela orientação preferencial de forma (OPF) de grãos de quartzo achatados, enquanto as lineações de estiramento possuem caimento sub-horizontal $\left(\sim 5^{\circ}\right)$ paralelo à orientação geral da zona de cisalhamento (Fig. 2B). A ZCPE pode ser individualizada nos domínios estruturais Caruaru e Gravatá a partir da variação das estruturas presentes e do grau metamórfico ao longo de sua extensão (Castellan et al., 2020).

O domínio Caruaru localiza-se a oeste da cidade de Caruaru até os arredores da cidade de Arcoverde (retângulo branco tracejado na Fig. 2A), e é composto por monzogranitos miloníticos grossos em fácies xisto verde alto. O domínio Gravatá situa-se a leste da cidade de Caruaru em direção à cidade de Recife (retângulo tracejado preto na Fig. 2A) e é constituído por ultramilonitos deformados em fácies xisto verde médio que exibem agregados recristalizados policristalinos de quartzo alternados com uma matriz polifásica fina (Castellan et al., 2020).

As amostras para este estudo foram coletadas ao longo da ZCPE, abrangendo seus setores oeste, central e leste (localização das amostras nos retângulos na Fig. 2A). Com o intuito de investigar a caracterização microestrutural, os mecanismos de deformação e a avaliação quantitativa da tensão diferencial, as amostras coletadas foram agrupadas de acordo com os domínios estruturais Caruaru e Gravatá, conforme a definição adotada em Castellan et al. (2020).

As rochas deformadas compreendem todo o espectro de milonitização, incluindo protomilonitos, milonitos e ultramilonitos, 

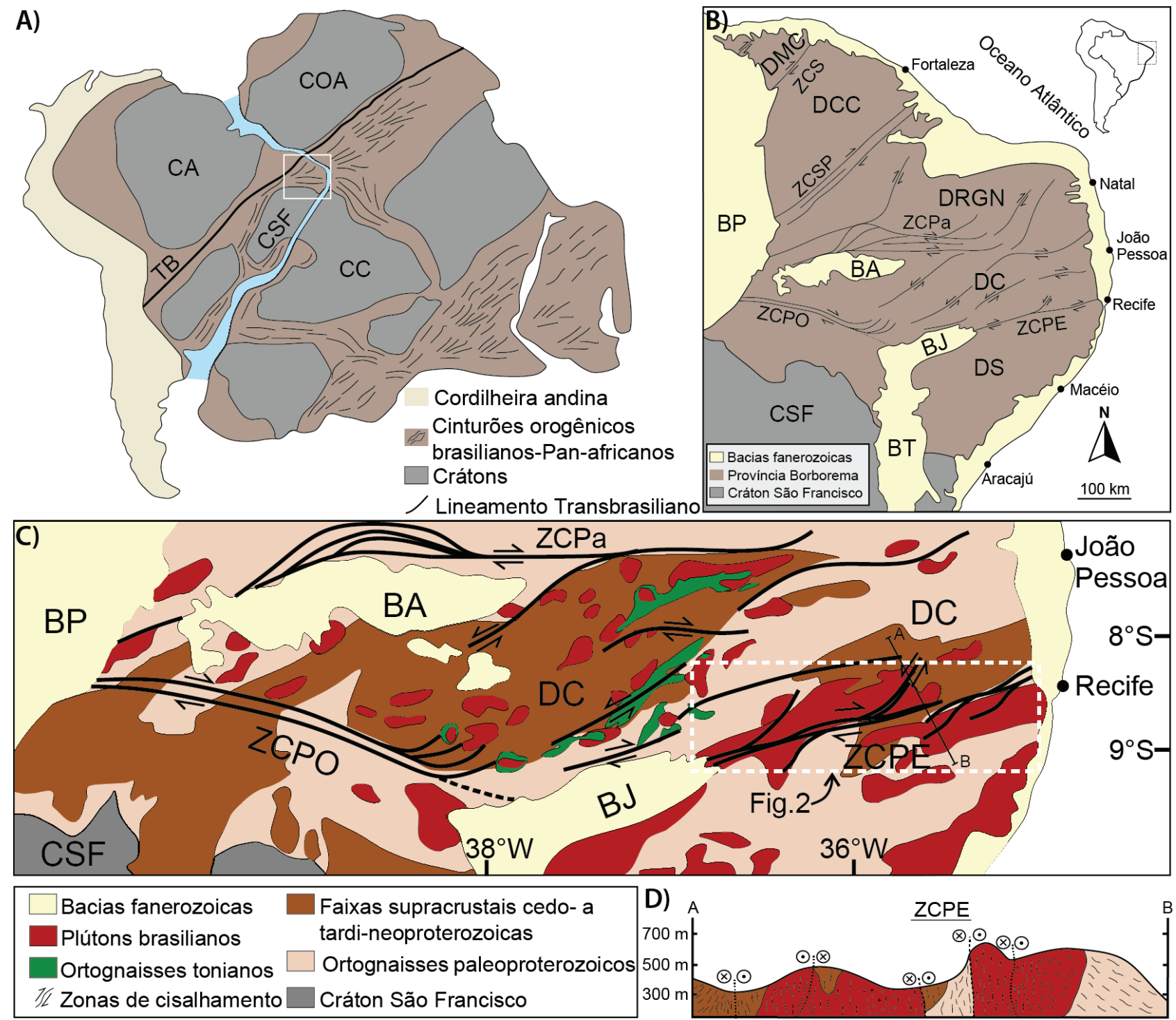

Figura 1. Contexto geológico regional. A) Ilustração da reconstrução dos continentes sul-americano e africano antes da fase drifte, com a identificação dos crátons (CA - Cráton Amazônico; COA - Cráton Oeste Africano; CSF - Cráton São Francisco; CC - Cráton do Congo), cinturões orogênicos neoproterozoicos e a cordilheira andina. A Província Borborema é destacada no retângulo branco; B) Mapa esquemático da Província Borborema dividida em Domínio Médio Coreaú (DMC), Domínio Ceará Central (DCC), Domínio Rio Grande do Norte (DRGN), Domínio Central (DC) e Domínio Sul (DS) e seus respectivos limites dados pelas zonas de cisalhamento Sobral (ZCS), Senador Pompeu (ZCSP), Patos (ZCPa), Pernambuco Oeste (ZCPO) e Pernambuco Leste (ZCPE). As bacias fanerozoicas representadas são a bacia do Parnaíba (BP), Araripe (BA), Jatobá (BJ) e Tucano (BT); C) Geologia simplificada do Domínio Central (DC) com destaque para a zona de cisalhamento Pernambuco Leste (retângulo tracejado); D) Perfil geológico simplificado da seção $A B$ identificada em (C) na zona de cisalhamento Pernambuco Leste. Modificado de Castellan et al. (2020).

Figure 1. Regional geological setting. A) Illustration of the reconstruction of the South American and African continents in the pre-drift phase, with the identification of cratons (AC - Amazonian Craton; WAC - West African Craton; SFC - São Francisco Craton; CC - Congo Craton), Neoproterozoic orogenic belts and the Andean belt. The Borborema Province is highlighted in the white rectangle; B) Schematic map of Borborema Province divided into the Médio Coreaú Domain $(M C D)$, the Ceará Central Domain (CCD), the Rio Grande do Norte Domain (RGND), the Central Domain (CD) and the Southern Domain (SD) and their respective limits given by Sobral (SSZ), Senador Pompeu (SPSZ), Patos (PaSZ), West Pernambuco (WPSZ) and East Pernambuco (EPSZ) shear zones. The Phanerozoic basins are the Parnaíba (BP), Araripe $(B A)$, Jatobá (BJ) and Tucano (BT) basins; $C$ ) Simplified geological map of the Central Domain (CD); white rectangle shows the East Pernambuco shear zone; D) Simplified AB cross-section identified in (C) in East Pernambuco shear zone. Modified from Castellan et al. (2020). 


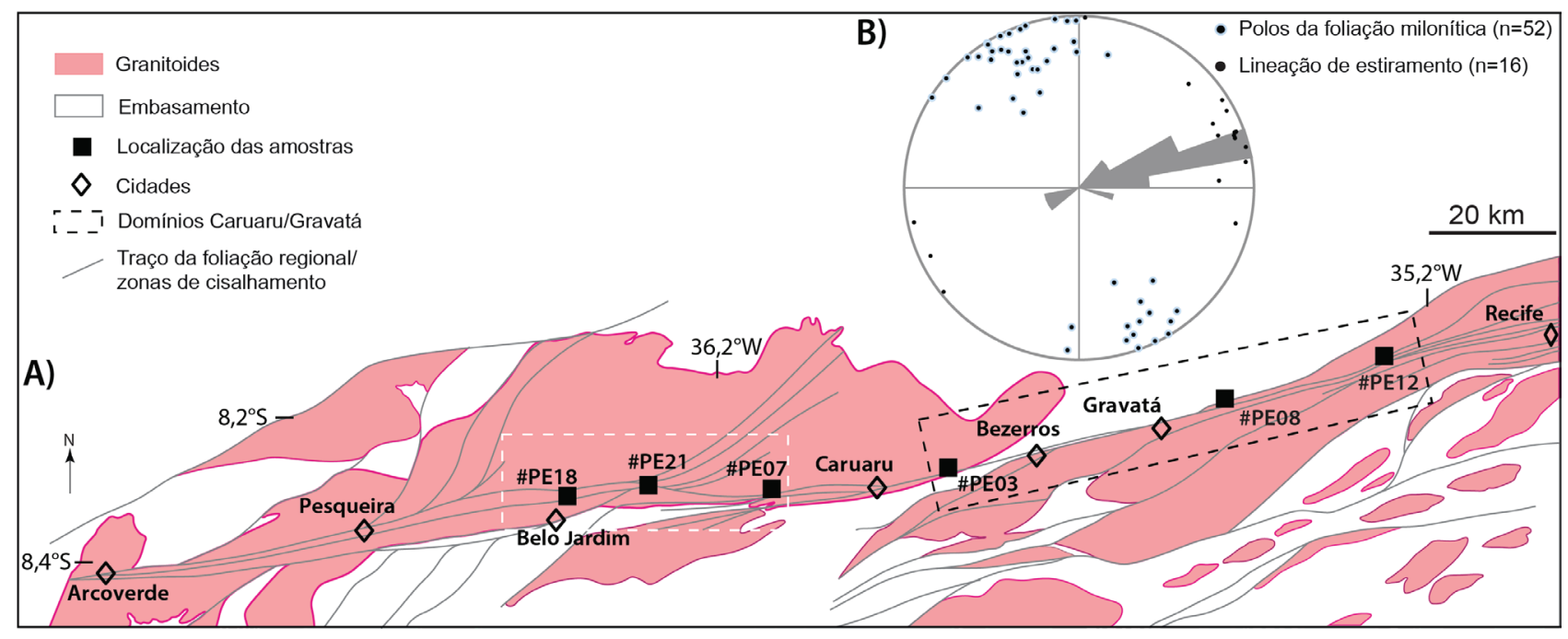

Figura 2. Zona de cisalhamento Pernambuco Leste. A) Mapa geológico esquemático da ZCPE com a localização das amostras coletadas. As amostras referentes aos domínios Caruaru e Gravatá estão individualizadas por meio dos retângulos tracejados branco e preto, respectivamente; B) Projeção estereográfica da foliação e lineação da ZCPE. Modificado de Castellan et al. (2020).

Figure 2. East Pernambuco shear zone. A) Schematic geological map of the EPSZ with the location of the collected samples. The samples referring to the Caruaru and Gravatá domains are individualized using the white and black dashed rectangles, respectively. B) Stereographic projection of foliation and lineation in the EPSZ. Modified from Castellan et al. (2020).

em sua maioria de composição granítica e consistindo em proporções similares de quartzo, K-feldspato e plagioclásio, com biotita ( \pm anfibólio) como principal fase ferromagnesiana. O quartzo é normalmente segregado em bandas recristalizadas monominerálicas que variam no grau de recristalização de acordo com o tipo de deformação.

\section{Métodos}

\subsection{Petrografia e análise microestrutural quantitativa}

\section{A caracterização petrográfica e} microestrutural dos granitoides milonitizados da zona de cisalhamento Pernambuco Leste foi realizada através da microscopia de luz polarizada e microscopia eletrônica de varredura. As lâminas polidas utilizadas correspondem ao plano perpendicular à foliação e paralelo à lineação das amostras coletadas. A distribuição do tamanho de grão foi analisada a partir das imagens obtidas através do Microscópio Eletrônico de Varredura (MEV) no Laboratório de Microscopia Eletrônica da Universidade de Brasília.
A individualização das populações de grãos e dos limites de suas formas e geometrias foi investigada com o uso de técnicas convencionais de análise de imagens em duas dimensões. o procedimento de análise de imagens em geociências utilizado neste estudo foi realizado com base nos protocolos apresentados nas revisões de Heilbronner \& Barret (2014) e LopezSanchez \& Llana-Funez (2015).

0 estudo petrográfico inicial das amostras selecionadas foi realizado a fim de identificar grãos recristalizados que ocorrem em equilíbrio textural com a microestrutura das rochas deformadas. Áreas representativas dos agregados foram então selecionadas para serem estudadas com o auxílio de técnicas de análise de imagem. Em cada imagem, uma rotina de processamento digital via ajuste das relações contraste / brilho foi realizada com o intuito de destacar os contornos de grãos e / ou transições de fase (Fig. 3A-C).

A delimitação dos contatos dos grãos de quartzo foi realizada por meio da digitalização manual das formas dos grãos em um aplicativo gráfico vetorial (e.g. Adobe Photoshop $\AA$ ). Os grãos foram contornados como polígonos com a área sendo a mais próxima possível à do grão 
(Fig. 3D). As bordas das bandas recristalizadas que mostraram a presença de protuberâncias de granulação fina migrando em direção ao limite das fitas recristalizadas foram excluídas da delimitação, uma vez que poderiam sugerir incrementos locais na tensão diferencial (Fig. 3B). Além disso, grãos periféricos e/ou marginais também foram descartados a fim de evitar os efeitos de interferência de fases secundárias (e.g. Herwegh et al., 2011)

Os resultados do contorno dos grãos em 2D foram convertidos em imagens raster e analisados com o software Image ${ }^{\circledR}$ para o cálculo da área de cada polígono (Fig. 3E). As áreas geradas a partir dos polígonos digitalizados representam as áreas dos grãos individuais e são analisadas estatisticamente (Fig. 3F-H). No total, foi produzido um conjunto de dados com o valor da área de 966 grãos.

\subsection{Estatísticas do tamanho de grão $e$ estimativas piezométricas}

Com base nas áreas seccionadas obtidas na análise de imagem, foram construídos histogramas contendo a estatística básica dos valores de tamanho de grão (média, mediana e desvio padrão).

As estimativas de tensão diferencial foram calculadas usando a calibração piezométrica de Stipp \& Tullis (2003), que é amplamente usada para agregados de quartzo recristalizados. A média do tamanho de grão obtida em cada amostra foi usada nos cálculos dos valores de tensão diferencial $(\mathrm{MPa})$. Os resultados são exibidos na forma de um gráfico contendo a variação da tensão diferencial ao longo da extensão da zona de cisalhamento Pernambuco Leste.

\section{Resultados}

\subsection{Observações de campo}

Os milonitos presentes no domínio Caruaru apresentam porfiroclastos grossos de $\mathrm{K}$-feldspato $(0,5-5 \mathrm{~cm})$ e bandas recristalizadas de quartzo imersos em uma matriz fina de feldspato recristalizado. Tanto os porfiroclastos quantos as bandas recristalizadas de quartzo são envoltos por bandas milimétricas máficas compostas por biotita e anfibólio, as quais definem a foliação milonítica anastomosada (Fig. $4 \mathrm{~A}$ e B).

O domínio Gravatá é constituído principalmente por ultramilonitos compostos por porfiroclastos de feldspato $(\leq 1 \mathrm{~cm})$ e bandas finas descontínuas de quartzo recristalizado, intercaladas com bandas máficas. O quartzo recristalizado está em contato com lamelas de biotita e muscovita que definem a foliação milonítica (Fig. 4C e D).

\subsection{Petrografia e microestruturas}

A ocorrência de bandas ricas em quartzo ao longo da foliação milonítica é identificada em meso- e microescala por toda a extensão da ZCPE (Fig. 4). As bandas podem atingir até $4 \mathrm{~mm}$ de espessura e consistem em raros porfiroclastos de quartzo grosso ( $\geq 200 \mu \mathrm{m}$ ) envoltos por agregados policristalinos recristalizados de quartzo fino (Fig. 5, 6 e 7A). Os processos de redução do tamanho de grão na rocha ocorrem a partir da formação de novos grãos nas margens dos porfiroclastos, resultando em trilhas de grãos finos com formas equigranulares e contatos retos e poligonais (Fig. 6). As bordas das bandas de quartzo apresentam contatos abruptos com a matriz fina quartzo-feldspática/máfica (Fig. 6C-F). O crescimento dos grãos nas margens das bandas é afetado pela interferência de fases secundárias (Herwegh et al., 2011).

A recristalização ao longo das margens dos porfiroclastos pode estar localmente associada a um componente de estiramento paralelo à direção geral de cisalhamento E-W/ENE. O estiramento resulta na formação de agregados de grãos alongados com $\sim 2 \mathrm{~mm}$ de comprimento (Fig. 5, 6C, 7A e E). Em algumas porções, os grãos de quartzo alongados apresentam uma orientação oblíqua em relação à foliação principal e destacam a componente destral do cisalhamento (Fig. 6C). As bordas dos clastos são parcialmente substituídas por agregados de granulação fina $(\sim 40 \mu \mathrm{m})$ e eventualmente apresentam contatos serrilhados marcados pela existência de pequenas protuberâncias ( 10 10 m; Fig. 7A-D). 


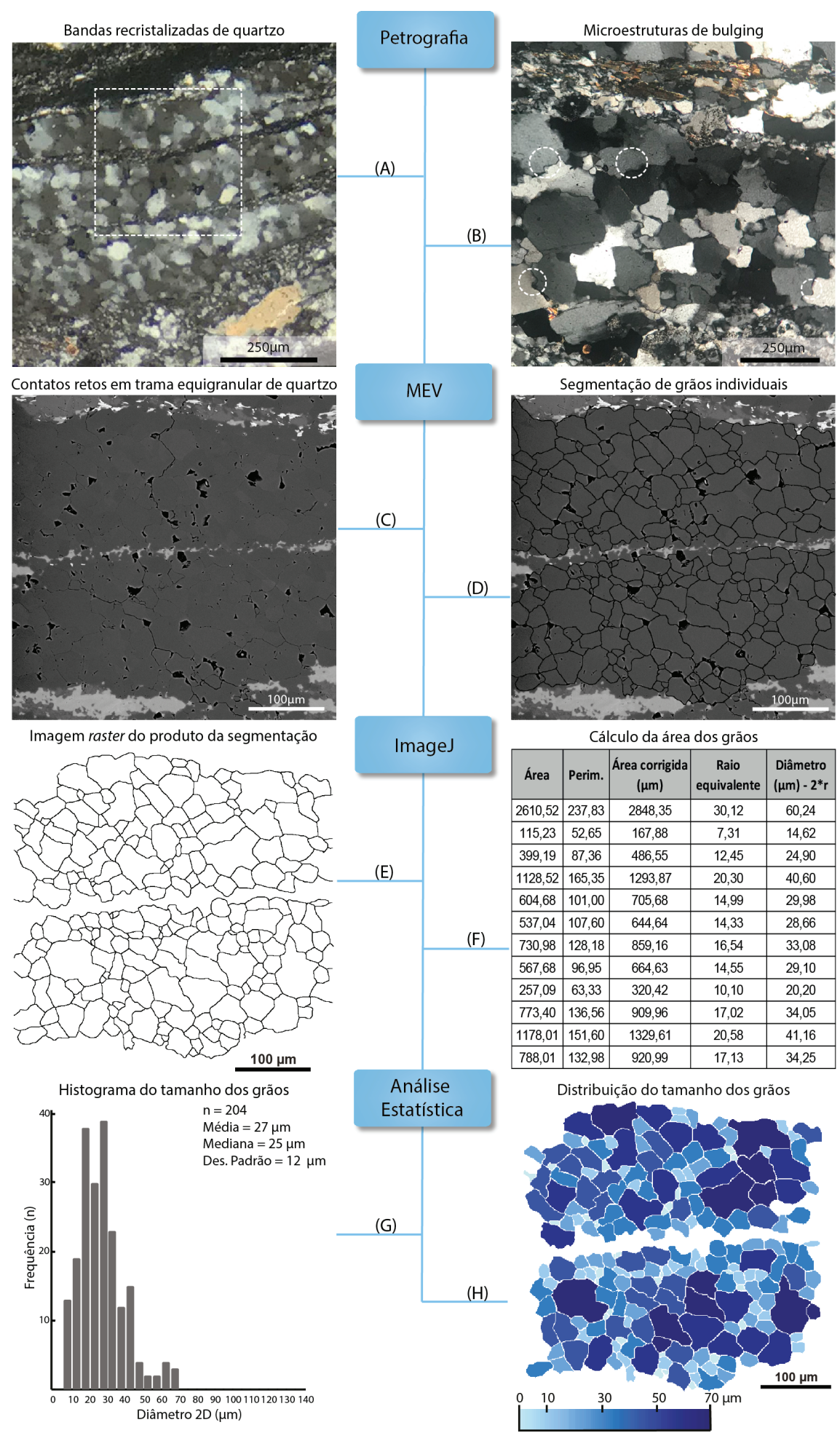

Figura 3. Etapas para a análise da distribuição do tamanho dos grãos. A) Seleção da área que apresenta equilíbrio textural com a microestrutura geral da rocha; B) Descarte das regiões que possuem microestruturas que registram a transição entre mecanismos de deformação; C) Aquisição de imagens de maior detalhe da área selecionada; D) Segmentação de grãos individuais; E) Análise da imagem dos contornos segmentados pelo software ImageJ®; F) Confecção de tabela com dados referentes às dimensões dos grãos pelo ImageJ(B; G) Criação de histogramas para análise estatística do tamanho de grão; H) Produção de imagem com a distribuição do tamanho de grão visível graficamente a partir de uma escala de cor.

Figure 3. Steps for analyzing grain size distributions. A) Selection of the area that shows textural equilibrium with the general microstructure of the rock; B) Disposal of the regions that have microstructures that record the transition of deformation mechanisms; C) Acquisition more detailed images of the selected area; D) Segmentation of individual grains; E) Image analysis of the segmented contours by the ImageJ® software; F) Construction of table with data of grain dimensions derived from Image $(\circledR ; G)$ Creation of histograms for statistical analysis of grain size; H) Production of image with the grain size distribution visible graphically from a color scale. 

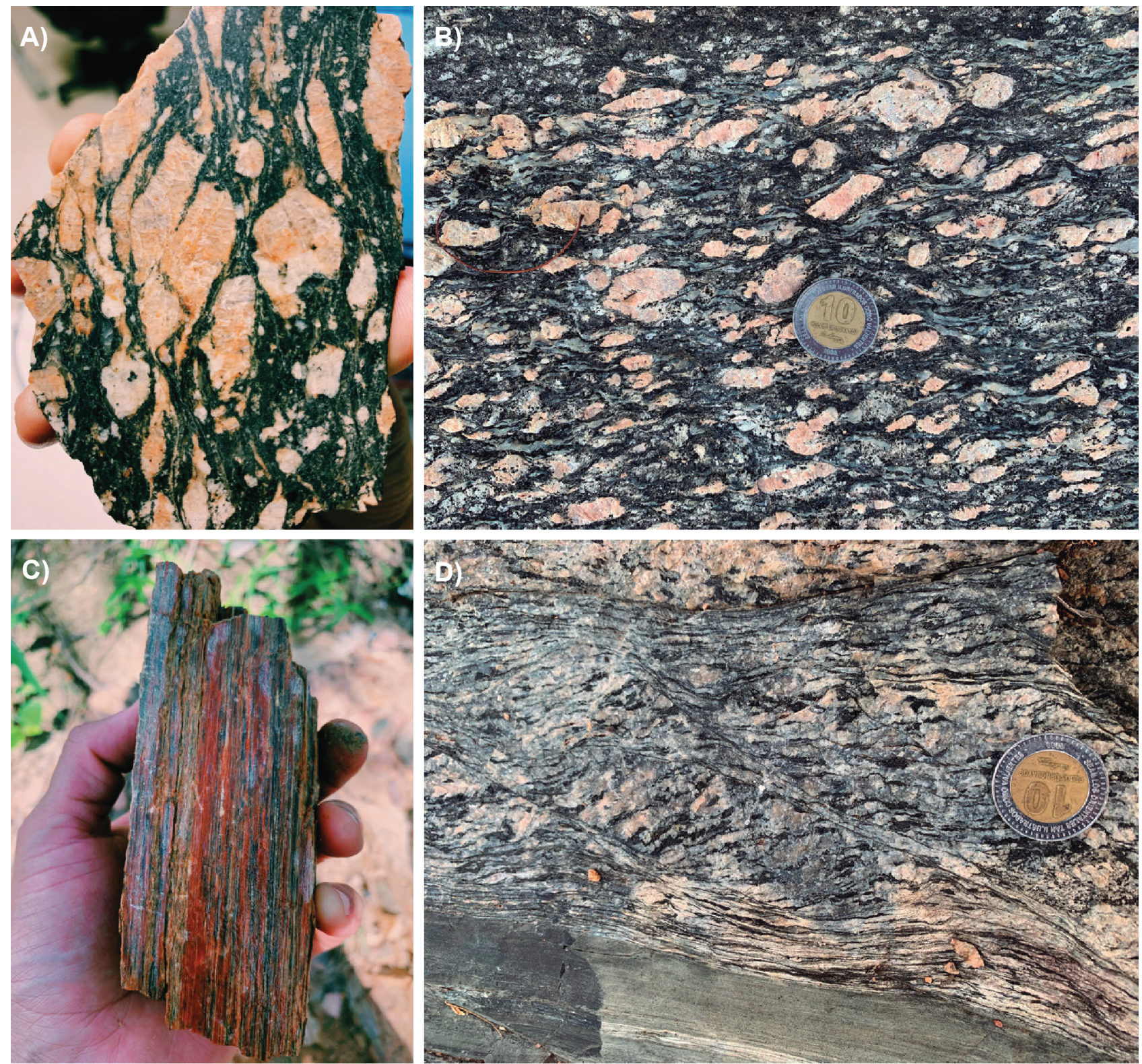

Figura 4. Observações de campo do domínio Caruaru (A e B) e Gravatá (C e D). A), B) Foliação milonítica anastomosada caracterizada por porfiroclastos sigmoidais centimétricos de $\mathrm{K}$-feldspato fraturados e envoltos por bandas recristalizadas ricas em quartzo de espessura milimétrica a centimétrica, e bandas máficas de biotita e anfibólio; C) Ultramilonito com bandamento composicional definido pela intercalação entre bandas finas quartzo-feldspáticas, bandas quartzosas descontínuas e bandas máficas de biotita e anfibólio de granulação fina; D) Contato abrupto entre banda ultramilonítica e granito foliado de granulação grossa. Modificado de Castellan et al. (2020).

Figure 4. Field observations of the Caruaru ( $A$ and B) and Gravatá ( $C$ and $D)$ domains. A), B) Anastomosed mylonitic foliation characterized by centimeter-scale, fractured and sigmoidal K-feldspar porphyroclasts, surrounded by $\mathrm{mm}$ - to $\mathrm{cm}$-scale quartz-rich bands, and mafic layers of biotite and amphibole. C) Ultramylonite with compositional banding defined by the alternation between fine-grained quartz-feldspar bands, discontinuous quartz bands and mafic bands of fine-grained biotite and amphibole. D) Abrupt contact between ultramylonitic band and coarse-grained foliated granite. Modified from Castellan et al. (2020). 


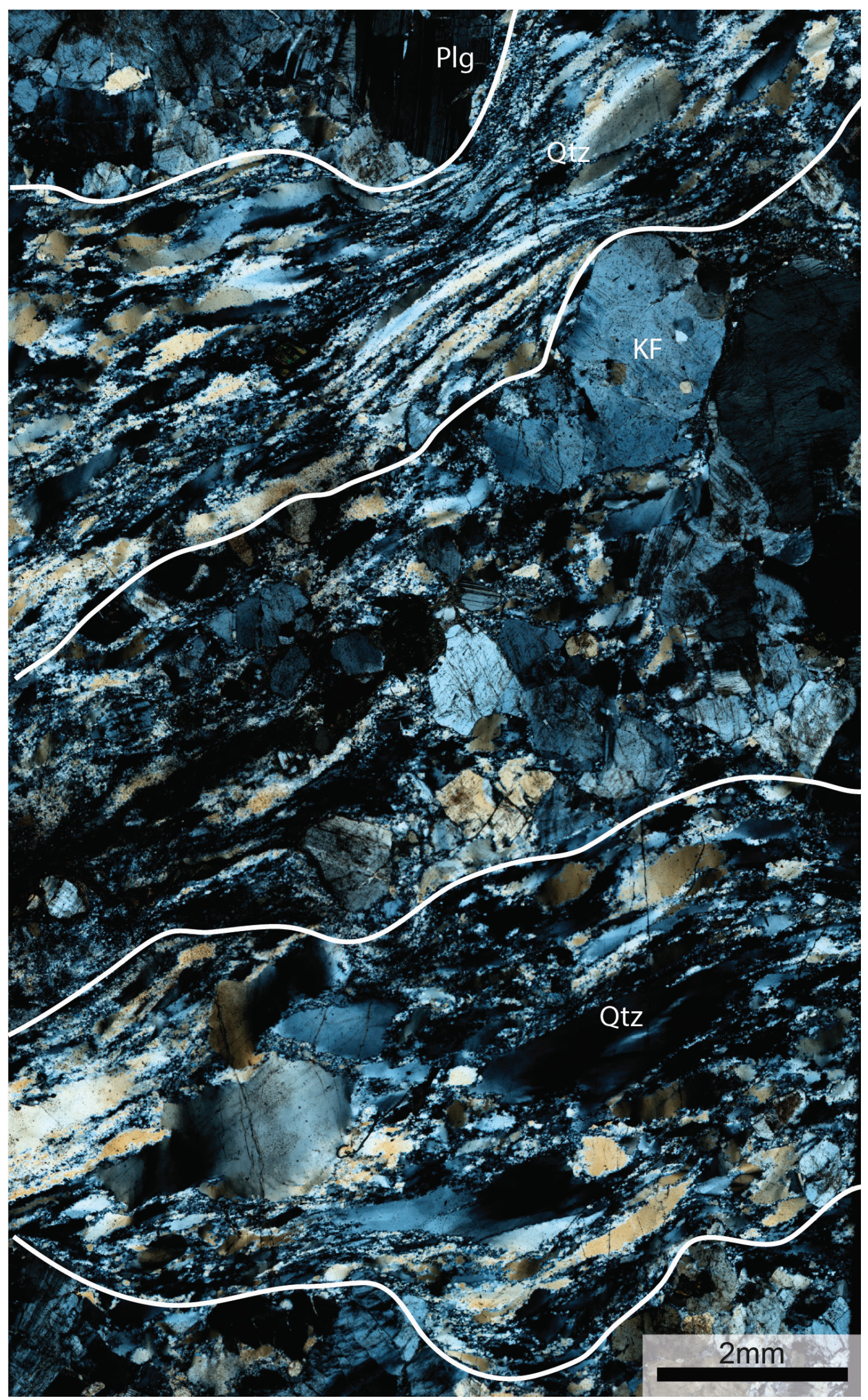

Figura 5. Bandas recristalizadas de quartzo (linhas brancas) em protomilonito da zona de cisalhamento Pernambuco Leste. As bandas são paralelas à foliação milonítica da rocha e comumente exibem porfiroclastos alongados e grãos recristalizados de quartzo, além de porfiroclastos reliquiares de feldspato.

Figure 5. Recrystallized quartz bands (white lines) in protomylonite from the East Pernambuco shear zone. The bands are parallel to the mylonitic foliation of the rock and commonly exhibit elongated porphyroclasts and recrystallized quartz grains, as well as relict feldspar porphyroclasts. 

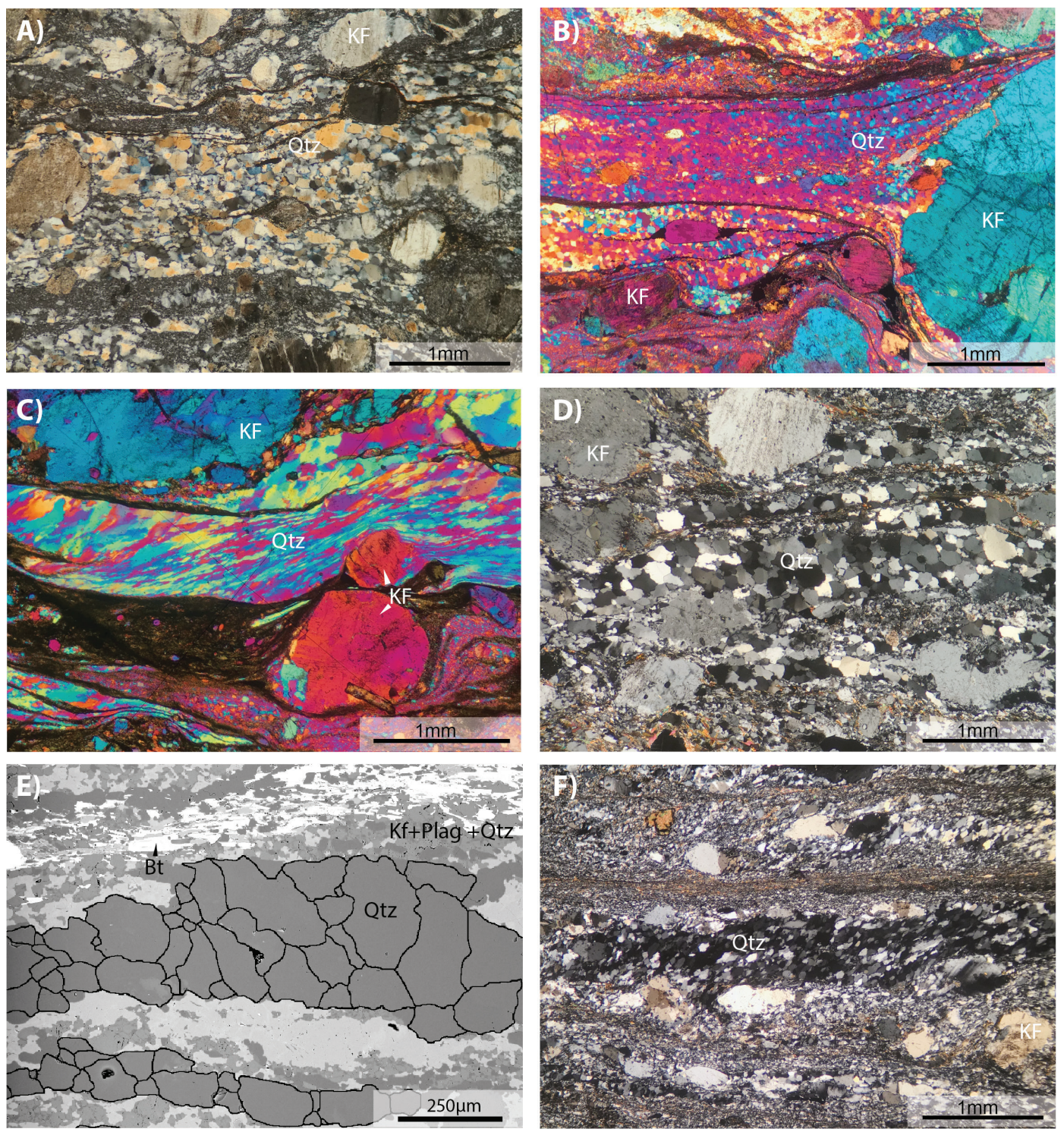

Figura 6. Microestruturas das bandas de quartzo ao longo dos domínios Caruaru (A-C) e Gravatá (D-F). A) Banda de quartzo composta por porfiroclastos de quartzo grosso $(>200 \mu \mathrm{m})$ circundados por agregados policristalinos recristalizados de quartzo fino. Fora da banda, há porfiroclastos de K-feldspato fraturados. As fraturas podem ser preenchidas por feldspatos recristalizados de granulação fina; B) Porfiroclastos subelípticos de K-feldspato com as bordas recristalizadas em contato com os agregados equigranulares de quartzo de grão fino $(\sim 30 \mu \mathrm{m})$. Placa de quartzo inserida; C) Aspecto sigmoidal das bandas de quartzo recristalizadas nas adjacências de clastos de K-feldspato contornados pela matriz filossilicática fina. Os grãos de quartzo apresentam um forte achatamento e a disposição da trama estrutural evidencia a cinemática destral. Placa de quartzo inserida; D) Bandas recristalizadas de quartzo intercaladas com agregados recristalizados finos de composição quartzo-feldspática e bandas finas de filossilicatos; E) Imagem de elétrons retroespalhados de ultramilonito com grãos de quartzo recristalizado em contato com agregados recristalizados de feldspatos e bandas filossilicáticas. Os grãos de quartzo estão individualizados para estudos de distribuição do tamanho dos grãos; F) Orientação preferencial de forma definindo assimetria oblíqua (destral) em banda rica em quartzo em ultramilonito. Porfiroclastos de feldspatos fraturados e alongados orientam-se segundo a direção de foliação. Filossilicatos ocorrem nas bordas das bandas ricas em quartzo e dos agregados recristalizados finos de quartzo e feldspatos.

Figure 6. Microstructure of quartz bands along the Caruaru $(A-C)$ and Gravatá $(D-F)$ domains. A) Quartz band composed of coarse-grained quartz porphyroclasts $(>200 \mu \mathrm{m})$ surrounded by polycrystalline aggregates of fine-grained quartz. Outside the band, there are fractured $K$-feldspar porphyroclasts. Fractures can be filled with fine-grained recrystallized feldspars; B) Sub-elliptical K-feldspar porphyroclasts with recrystallized boundaries in contact with fine-grained, equigranular quartz aggregates $(\sim 30 \mu \mathrm{m})$. Quartz plate inserted; C) Sigmoidal aspect of recrystallized quartz bands in the vicinity of $K$-feldspar clasts surrounded by the fine-grained phyllosilicate matrix. The quartz grains show a strong degree of flattening, and the geometry of the structural fabric suggests dextral asymmetry. Quartz plate inserted; D) Recrystallized quartz bands interconnected with fine recrystallized aggregates of quartz-feldspathic composition and fine-grained bands of phyllosilicates; E) Backscatter electron image of ultramylonite with recrystallized quartz grains in contact with recrystallized feldspar aggregates and phyllosilicate bands. Quartz grains are individualized for studies of grain size distribution; F) Shape preferred orientation (SPO) defining oblique asymmetry (dextral) in quartz-rich band in ultramylonite. Porphyroclasts of fractured and elongated feldspar are oriented according to the orientation of the foliation. Phyllosilicates occur at the boundaries of quartz-rich bands and fine recrystallized quartz and feldspar aggregates. 
As bordas dos subgrãos nos porfiroclastos de quartzo são alongadas seguindo a orientação do grão hospedeiro (Fig. 7A). Eles variam em largura, sendo maiores $(\sim 30-50 \mu \mathrm{m})$ nos agregados de grãos alongados do que nos novos grãos que circundam os clastos ( $20 \mu \mathrm{m}$; Fig. 7AC). Quando perto das bordas dos porfiroclastos, os limites de subgrãos mostram um diâmetro similar aos agregados recristalizados $(\sim 15-20$ $\mu \mathrm{m}$; Fig. 7D).

Os porfiroclastos de feldspato fora das bandas ricas em quartzo estão fraturados e deslocados por microfalhas (Fig. 7E e F). Os fragmentos resultantes apresentam formas $e$ tamanhos irregulares de até $2 \mathrm{~mm}$. As fraturas podem ser preenchidas localmente por feldspato recristalizado de granulação fina ( $5 \mu \mathrm{m}$; Fig. 7F). A deformação plástica do feldspato é observada através da geminação mecânica em clastos de plagioclásio (Fig. 7E e F). Produtos de alteração (e.g. sericita, epidoto) ocorrem como trilhas de granulação fina paralelas à foliação da rocha (Fig. $6 F)$ ou contornando os porfiroclastos grossos de feldspato.

\subsection{Distribuição do tamanho dos grãos}

As microestruturas representativas dos agregados recristalizados de quartzo e os principais valores do tamanho de grão obtidos a partir da análise das imagens das bandas de quartzo recristalizado do setor oeste da ZCPE (domínio Caruaru, retângulo branco tracejado na Fig. 2A) são exibidos na figura 8. Os dados referentes ao setor leste (domínio Gravatá, retângulo tracejado preto na Fig. 2A) são ilustrados na figura 9.

As amostras representativas do domínio Caruaru (\#PE18, \#PE21, \#PE07) apresentam valores médios de tamanho de grão de 50 m, 27 $\mu \mathrm{m}$ e $94 \mu \mathrm{m}$, respectivamente. A mediana é de 44 $\mu \mathrm{m}, 25 \mu \mathrm{m}$ e $91 \mu \mathrm{m}$ e o desvio padrão de $28 \mu \mathrm{m}$, $12 \mu \mathrm{m}$ e $35 \mu \mathrm{m}$, respectivamente.

A distribuição do tamanho de grão das amostras referentes aos milonitos do domínio Gravatá (\#PE03, \#PE12, \#PE08) exibe médias de $82 \mu \mathrm{m}, 40 \mu \mathrm{m}$ e $30 \mu \mathrm{m}$, e mediana de $70 \mu \mathrm{m}, 35$ $\mu \mathrm{m}$ e $30 \mu \mathrm{m}$, respectivamente. 0 desvio padrão dos dados analisados é de $48 \mu \mathrm{m}, 24 \mu \mathrm{m}$ e 14 $\mu \mathrm{m}$, respectivamente.

\subsection{Estimativas da tensão diferencial por piezometria}

Os valores de tensão diferencial (em MPa) foram calculados para todo o conjunto de dados e distribuídos ao longo dos domínios oeste e leste da ZCPE. Os principais resultados são ilustrados na figura 10. A localização das amostras está indicada na figura $2 \mathrm{~A}$.

O gráfico traçado na figura 10 mostra um aumento nos valores de tensão diferencial, variando de 30 a $48 \mathrm{MPa}$ dentro dos limites do domínio Caruaru (definido na Fig. 2A). Perto da cidade de Caruaru, as estimativas de tensão diferencial diminuem para $18 \mathrm{MPa}$ devido aos tamanhos médios de grão de $94 \mu \mathrm{m}$, medidos em bandas recristalizadas de quartzo de granulação grossa (amostra \#PE07; Fig. 8).

As estimativas de tensão diferencial no domínio Gravatá mostram um aumento gradual dos valores estimados, de 20 para 45 MPa, em direção à terminação leste da zona de cisalhamento (Fig. 8); um aumento incremental nos valores de tensão é observado ao longo do domínio, aproximando-se da média do domínio Caruaru ( 32 MPa).

\section{Discussão}

\subsection{Deformação do feldspato}

Os porfiroclastos grossos de K-feldspato e plagioclásio apresentam fraturas e falhas preenchidas por grãos recristalizados, as quais evidenciam a atuação de mecanismos essencialmente rúpteis-dúcteis (Fig. $7 \mathrm{E}$ e F). O fraturamento dos porfiroclastos resulta na progressiva fragmentação dos grãos rígidos e recristalização dos mesmos em grãos finos incorporados à matriz quartzo-feldspática. A composição química distinta entre os grãos recristalizados e os clastos magmáticos de feldspato (Castellan et al., 2020), juntamente com a existência de produtos de alteração como sericita e epidoto ao longo das bordas e das fraturas dos clastos, indicam que o fraturamento dos clastos ocorreu em condições de baixa temperatura, possivelmente associados com a circulação de fluidos ao longo da zona de cisalhamento. 

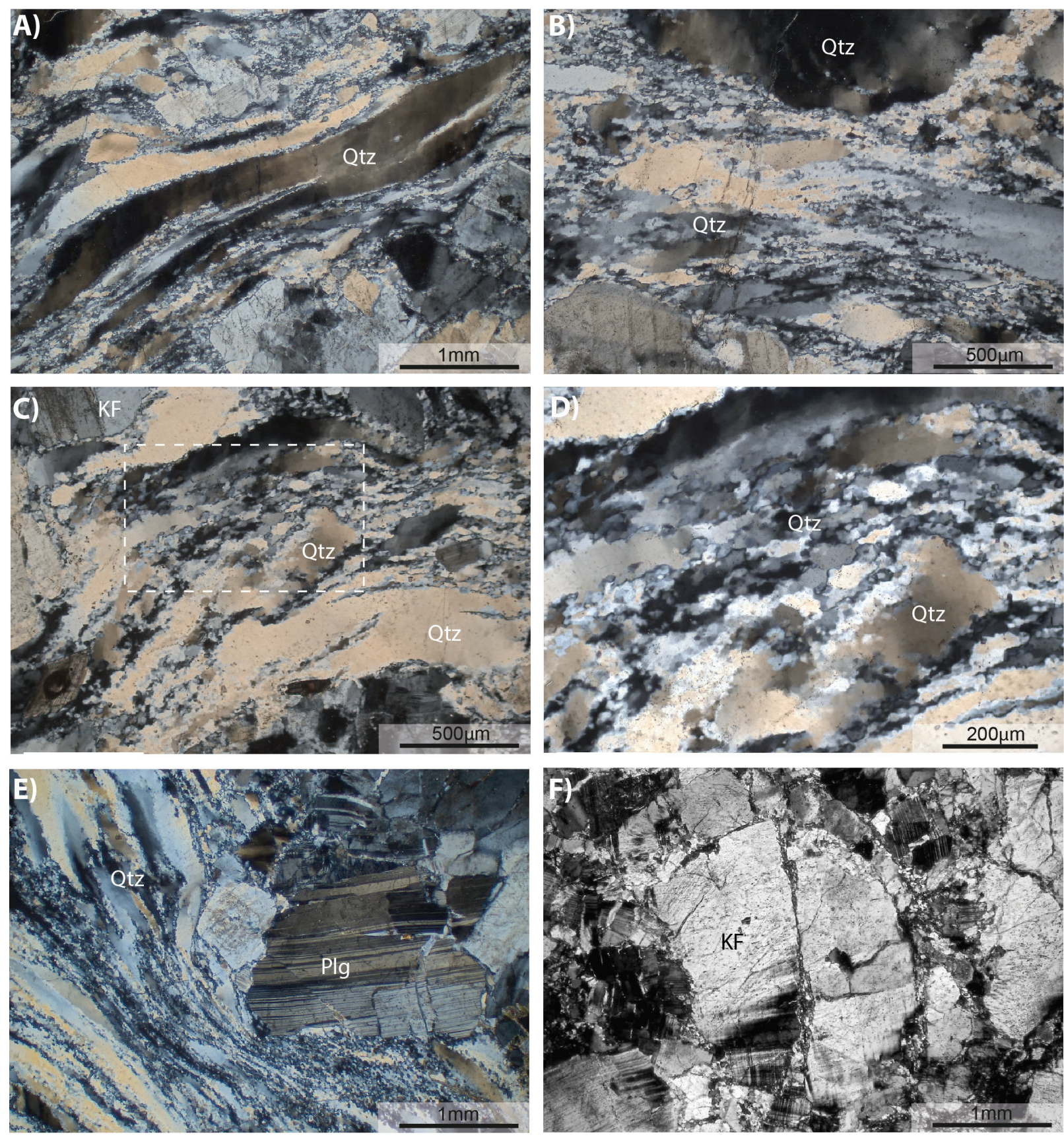

Figura 7. Microestruturas da zona de cisalhamento Pernambuco Leste. A) Clastos alongados de quartzo com extensa formação de subgrãos e recristalização ao longo das bordas para agregados finos de quartzo ( 40 $\mu \mathrm{m})$. Ao longo das bordas dos clastos de quartzo ocorrem reentrâncias granulares finas (bulges); B) Formação de grão finos de quartzo recristalizado $(\sim 20 \mu \mathrm{m})$ ao longo das bordas dos clastos de quartzo. 0 clasto de quartzo na porção superior da imagem exibe subgrãos; C) Banda recristalizada de quartzo com intensa recristalização das bordas dos clastos e formação de novos grãos; D) Detalhe marcado na figura 7C; E) Clastos de plagioclásio fraturados e com geminação mecânica em contato com banda rica em quartzo. A banda apresenta quartzo grosso alongado com subgrãos e recristalização para grãos finos ao longo das bordas; F) Porfiroclastos de K-feldspato com deslocamentos em escala de micrômetros causados por falhas transgranulares e preenchidos por agregados finos de feldspato recristalizado. Apresenta ainda geminação mecânica e recristalização de suas bordas.

Figure 7. Microstructures of the East Pernambuco shear zone. A) Elongated quartz clasts with extensive sub-grain formation and recrystallization along the boundaries into fine-grained quartz aggregates $(\sim 40 \mu m)$. Fine-grained bulges occur along the boundaries of quartz clasts; B) Formation of fine-grained recrystallized quartz $(\sim 20 \mu \mathrm{m})$ along the boundaries of quartz clasts. The quartz clast in the upper portion of the image shows the presence of sub-grains; $C$ ) Quartz band with intense recrystallization of the borders of the clasts and formation of new grains; D) Detail of inset highlighted in figure 7C; E) Fractured plagioclase clasts with mechanical twinning in contact with a quartz-rich band. The band presents coarse-grained elongated quartz with subgrains and recrystallized, fine grains along its boundaries. F) K-feldspar porphyroclasts with micrometer-scale displacement caused by transgranular faults that are filled by fine-grained aggregates of recrystallized feldspar. It also presents mechanical twinning and grain boundary marginal recrystallization. 


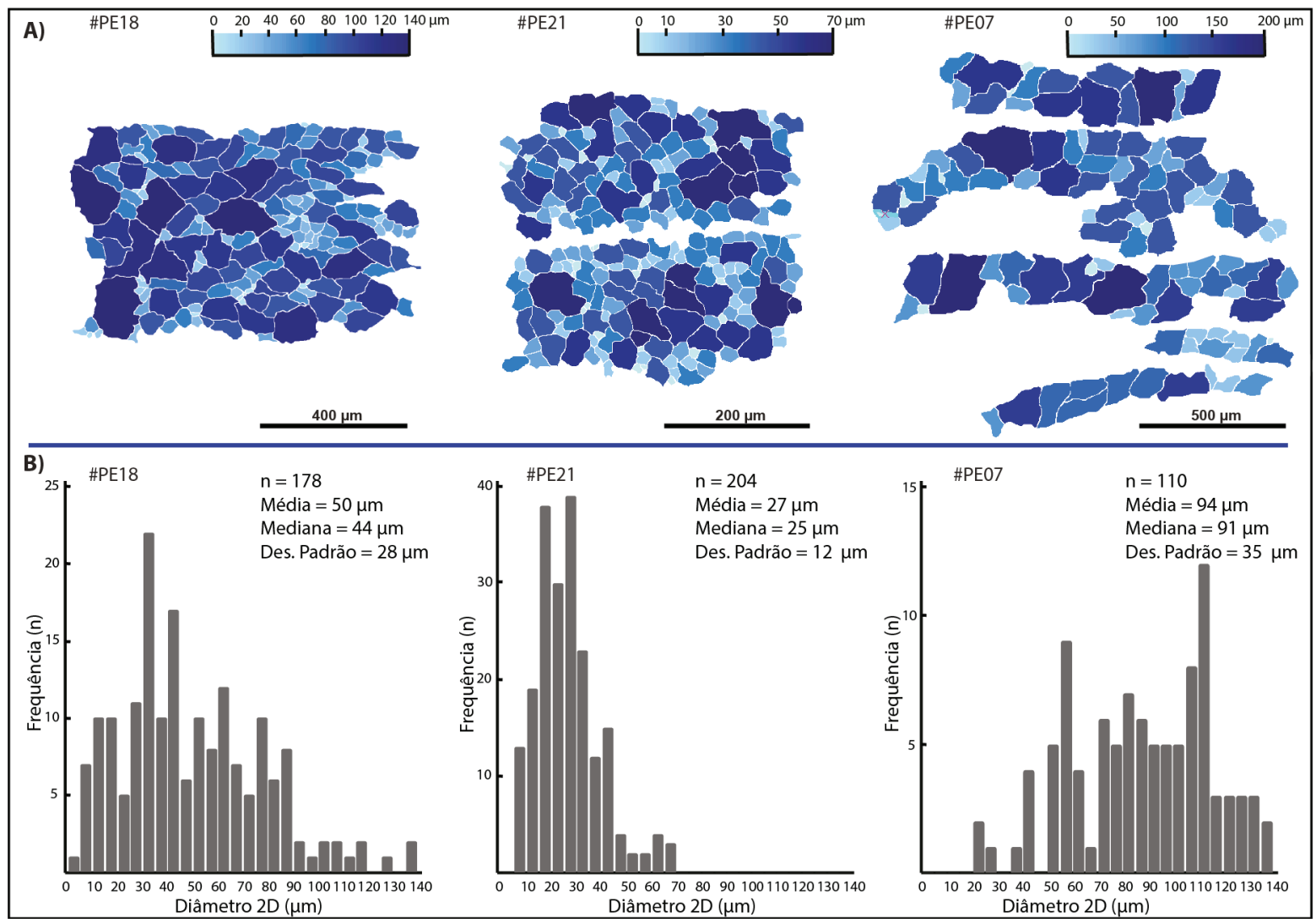

Figura 8. Frequência de distribuição de tamanho de grão de amostras representativas do domínio Caruaru. A) Imagem codificada por cores mostrando a distribuição de tamanho de grão em bandas de quartzo recristalizadas. A escala de cores é dada de acordo com o tamanho do grão; B) Histogramas de frequência para a distribuição de tamanho de grão recristalizado mostrado em $(A)$.

Figure 8. Grain size distribution frequency of representative samples from Caruaru domain. A) Color-coded image showing the grain size distribution in recrystallized quartz bands. The color scale is given according to the grain size; $B$ ) Frequency histograms for the recrystallized grain size distribution shown in (A).

\subsection{Mecanismos de deformação erecristalização das bandas ricas em quartzo}

Apesar da diferenciação estrutural e 2 (a) metamórfica dos milonitos da ZCPE entre os domínios Caruaru e Gravatá (Castellan et al., 2020), as bandas recristalizadas de quartzo são comuns ao longo de toda a extensão da ZCPE (Fig. 6 e 7). A presença de subgrãos nos raros porfiroclastos de quartzo sugere que estes clastos acomodaram incrementos da tensão diferencial por meio de fluência de deslocações (Hirth \& Tullis, 1992; Fig. 7A-D). As microestruturas dadas por: i) grãos recristalizados de quartzo com tamanhos similares aos subgrãos presentes nos porfiroclastos (Fig. 7C e D), eii) formação de novos grãos de quartzo no estado sólido com tamanhos equigranulares e com contatos retilíneos (Fig. 6B, $D, E$ e F), sugerem que a recristalização do quartzo e a subsequente formação dos agregados recristalizados segregados em bandas ocorreu essencialmente por meio de recristalização rotacional de subgrãos (Stipp et al., 2002; Tullis, 2002).

A recristalização dinâmica por rotação de subgrão é o mecanismo de deformação dominante nas bandas recristalizadas de quartzo ao longo de toda a ZCPE, e corresponde ao Regime 2 de Hirth \& Tullis (1992). Localmente, no domínio Gravatá, observam-se protuberâncias (bulges) nas extremidades dos clastos de quartzo formadas pela recristalização por migração de borda lenta dos grãos (Bulging, BLG; Fig. 7A-D). Nessas porções ocorre a combinação dos mecanismos de recristalização tanto por migração de borda de grão lenta quanto por rotação de subgrão. A presença de bulges nas extremidades dos clastos sugere que incrementos locais da tensão diferencial foram acomodados na borda dos clastos, os 


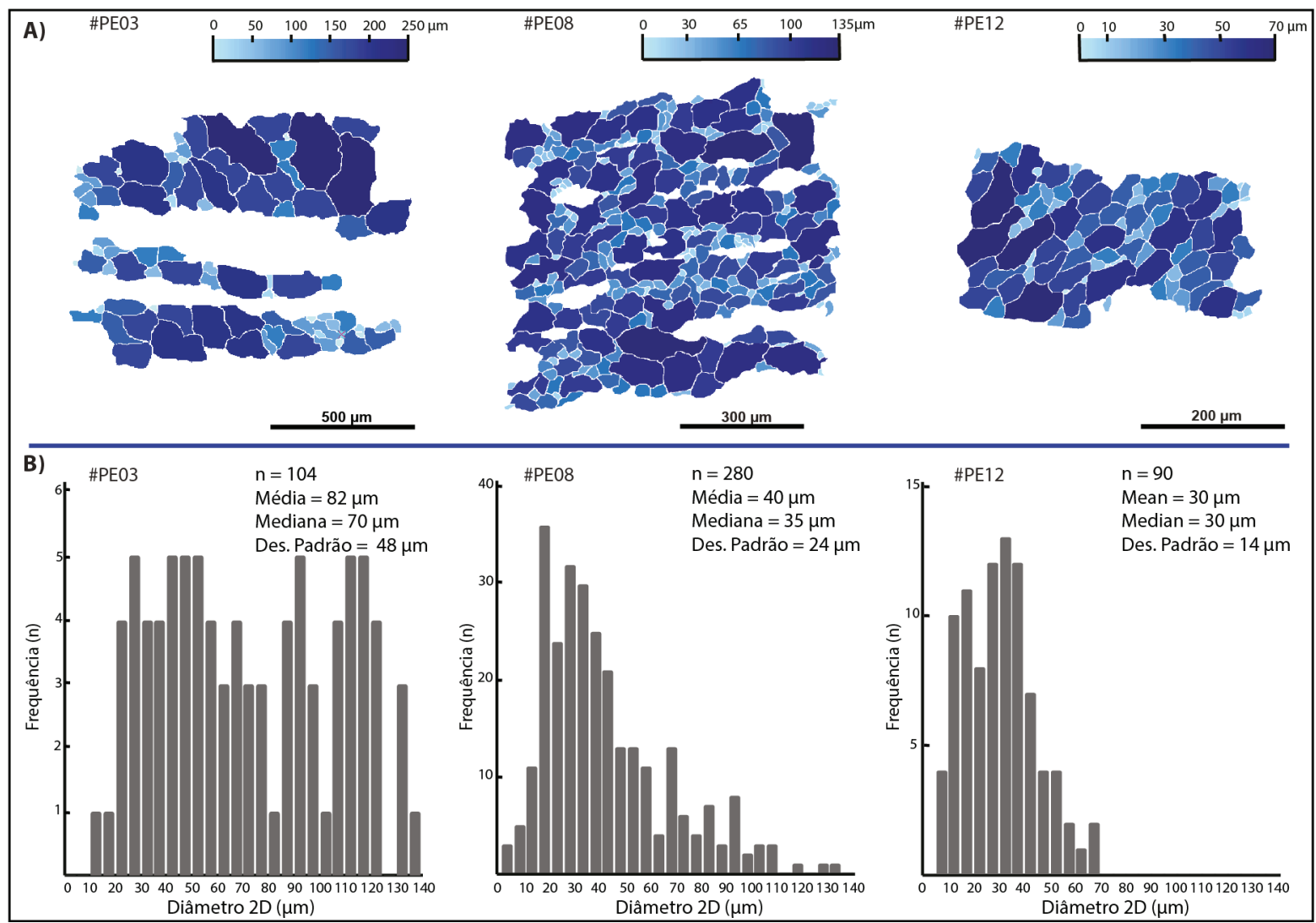

Figura 9. Frequência de distribuição de tamanho de grão de amostras representativas do domínio Gravatá. A) Imagem codificada por cores mostrando a distribuição de tamanho de grão em bandas de quartzo recristalizadas. A escala de cores é dada de acordo com o tamanho do grão; B) Histogramas de frequência para a distribuição de tamanho de grão recristalizado mostrado em $A$.

Figure 9. Grain size distribution frequency of representative samples from Gravatá domain. A) Color-coded image showing the grain size distribution in recrystallized quartz bands. The color scale is given according to the grain size; $B$ ) Frequency histograms for the recrystallized grain size distribution shown in A.

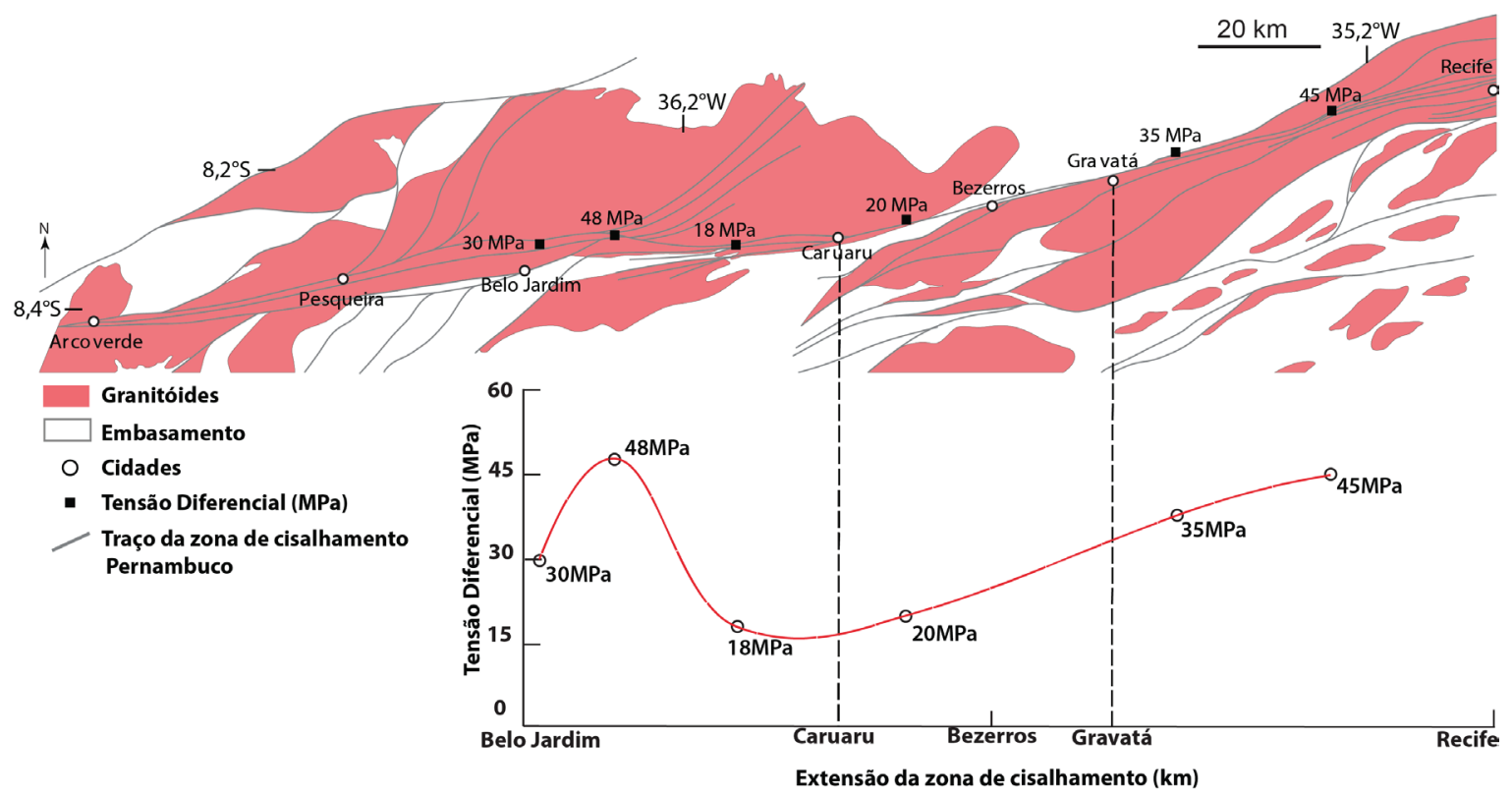

Figura 10. Estimativas de tensão diferencial plotadas ao longo da extensão da ZCPE. A curva do gráfico representa a variação dos valores de tensão diferencial com base no tamanho do grão de quartzo recristalizado nos agregados analisados. A projeção geográfica de localidades-tipo (linhas pretas tracejadas) é informada para referência. Ver texto para discussão.

Figure 10. Differential stress estimates plotted along the length of the EPSZ. The red curve represents the variation of the differential stress values based on the grain size of the recrystallized quartz in the analyzed aggregates. The geographic projection of locations (dashed black lines) is reported for reference. See text for discussion. 
quais podem estar associados com a tensão rúptil registrada nos grãos grossos fraturados de feldspato (Fig. 7E e F).

Portanto, o presente banco de dados nos permite concluir que a formação das bandas ricas em quartzo ocorreu essencialmente pelo mecanismo de recristalização por rotação de subgrãos, em condições metamórficas de fácies xisto-verde médio a alto (e.g. Castellan et al., 2020). Tais condições sugerem que a deformação dúctil foi eficientemente localizada nos agregados recristalizados de quartzo, enquanto o restante da rocha foi deformado essencialmente por fraturamento associado com fluência difusiva/ dissolução-precipitação na presença de fluidos (e.g. Viegas et al., 2016; Castellan et al., 2020).

\subsection{Significado das estimativas da tensão diferencial ao longo da ZCPE}

Os valores calculados de tensão diferencial ao longo da extensão da zona de cisalhamento Pernambuco Leste exibem uma variação contínua (Fig. 10). No setor ocidental da estrutura, equivalente ao domínio Caruaru de Castellan et al. (2020), valores intermediários de tensão diferencial (30 MPa) exibem incrementos progressivos (48 $\mathrm{MPa}$ ) antes de registrarem diminuição das estimativas no setor central da zona de cisalhamento (Fig. 10). Estas características sugerem que a deformação dúctil é eficientemente acomodada nas bandas recristalizadas de quartzo no domínio Caruaru, e a diminuição dos valores de tensão diferencial próximos à cidade de Caruaru coincide com a transição estrutural entre ambos os domínios caracterizados ao longo da extensão da zona de cisalhamento. Com efeito, a predominância de mecanismos de dissolução-precipitação assistidos por fluidos no domínio Gravatá, evidenciados pelas condições metamórficas decrescentes e a formação de assembleias minerais de baixa-temperatura (e.g. filossilicatos; Fig. 6), resulta em uma ineficiência da acomodação da deformação no estado sólido nesta região, resultando, assim, na diminuição dos valores de tensão diferencial registrados no setor central da estrutura (Fig. 10).

Contudo, o segmento leste da ZCPE é marcado por um aumento regular das estimativas de tensão diferencial em direção à terminação oriental da estrutura (Fig. 10). Os valores baixos ( $20 \mathrm{MPa}$ ) tendem a estabilizar em torno de $\sim 45 \mathrm{MPa}$, uma estimativa similar aos valores calculados para a terminação oeste da ZCPE (Fig. 10).

Estes dados sugerem que as bandas recristalizadas de quartzo registram incrementos locais nos valores de tensão diferencial que podem estar associados com a partição heterogênea da deformação entre processos de recristalização dinâmica e mecanismos de fragmentação mecânica e/ou dissoluçãoprecipitação, observados essencialmente nos grãos de quartzo e feldspato, respectivamente. A deformação dúctil nos agregados de quartzo resulta na nucleação de bandas recristalizadas que localizam a deformação ao longo da zona de cisalhamento, enquanto a redução do tamanho do grão por processos rúpteis é observada nos grãos grossos de feldspato. A combinação entre esses processos, invariavelmente assistidos por fluidos, resulta nas estimativas heterogêneas dos valores de tensão diferencial registrados nas bandas recristalizadas de quartzo.

Dessa forma, o presente banco de dados sugere que a zona de cisalhamento Pernambuco Leste registra uma evolução reológica particionada entre mecanismos dúcteis registrados em agregados recristalizados de quartzo, e mecanismos rúpteis e rúpteis-dúcteis observados em clastos grossos de feldspato. A partição reológica entre fases deformacionais durante a deformação de granitoides tem sido amplamente reportada e documentada em diversos estudos que abordam a evolução crustal de zonas de cisalhamento continentais (e.g. Park et al., 2006; Ishii et al., 2007; Herwegh et al., 2011).

\subsection{Implicações tectônicas}

A caracterização das tramas tectônicas e condições de P, T ao longo da ZCPE foram recentemente investigadas por Castellan et al. (2020). Os autores concluíram que a ZCPE evoluiu de forma heterogênea, registrando o desenvolvimento de tramas rúpteis-dúcteis em condições intermediárias a altas da fácies xisto 
verde. Adicionalmente, os autores ressaltaram a atuação dos mecanismos de rotação de subgrãos em agregados recristalizados de quartzo no setor oeste da estrutura, enquanto que a porção oriental é marcada pela transição do mecanismo de recristalização bulging (Bulging recrystallization - BLG) para a recristalização por rotação de subgrãos (Subgrain Rotation Recrystallization - SGR), na presença de fluidos.

Nossos resultados são consistentes com essas observações e as estendem, visto que: i) a nucleação das bandas recristalizadas ricas em quartzo se constitui em um mecanismo eficiente de localização da deformação dúctil ao longo da ZCPE; ii) oscilações nas estimativas de tensão diferencial ao longo da estrutura refletem o grau de recristalização das bandas de quartzo, as quais sofrem influência do particionamento entre os diferentes mecanismos de deformação atuantes na zona de cisalhamento Pernambuco Leste, e iii) a tendência à estabilização dos valores de tensão diferencial no setor oriental da estrutura ressalta a importância da fluência de deslocações na acomodação da deformação ao longo da zona de cisalhamento.

Dessa forma, nosso estudo permite concluir que a curva de tensão diferencial observada ao longo da ZCPE reflete a eficiência da recristalização dinâmica em estabilizar as condições deformacionais durante o desenvolvimento de estruturas rúpteis-dúcteis. O efetivo particionamento entre componentes reológicos distintos (i.e., recristalização dinâmica e fraturamento) resulta na formação de bandas recristalizadas ricas em quartzo que promovem significativa localização da deformação dúctil, enquanto as fases reologicamente menos suscetíveis à recristalização no estado sólido deformam essencialmente pela combinação entre fraturamento e dissolução-precipitação. Tais características, comuns em zonas de cisalhamento exumadas em profundidades associadas à transição rúptil-dúctil, fornecem informações importantes sobre os processos de localização da deformação em zonas de cisalhamento crustais (e.g. Handy et al., 2007).

Adicionalmente, nossos resultados permitem sugerir que os mecanismos de recristalização dinâmica em bandas monominerálicas de quartzo possuem papel importante na reologia de zonas de cisalhamento nucleadas na presença de magma. A zona de cisalhamento Patos (Archanjo et al., 2008; Archanjo et al., 2013; Viegas et al., 2013; Viegas et al., 2014), de direção E-W e localizada na terminação norte da Zona Transversal (Fig. 1B), é caracterizada por recristalização no estado sólido em ortognaisses de alta temperatura, enquanto que mecanismos de fluxo granular magmático dominam em migmatitos (Viegas et al., 2014). Embora nucleada em profundidades correspondentes à crosta intermediária a inferior, as porções não-fundidas desta estrutura, marcadas pela presença de ortognaisses miloníticos de grão grosso, podem ser correlacionadas com a milonitização de alta temperatura registrada nas bandas recristalizadas de quartzo na ZCPE; em ambas as zonas de cisalhamento, a componente dúctil da deformação é eficientemente localizada em agregados recristalizados de quartzo, enquanto que microfraturamento, fluxo granular magmático e mecanismos de dissoluçãoprecipitação são observados nas outras fases, e.g. feldspatos.

\section{Conclusões}

Com base no estudo das estruturas observadas em meso- e microescala nos granitoides milonitizados da ZCPE, associadas às estimativas de tensão diferencial obtidas a partir da análise do tamanho de grão nas bandas recristalizadas ricas em quartzo, as seguintes considerações podem ser destacadas:

Os agregados de quartzo localizam a deformação dúctil ao longo da ZCPE a partir da nucleação de bandas recristalizadas ricas em quartzo. Estas bandas ricas em quartzo registram os incrementos locais de tensão diferencial de acordo com o seu grau de recristalização. Em contrapartida, os porfiroclastos de feldspato registram a redução do tamanho do grão por meio de mecanismos rúpteis. Desta forma, os valores heterogêneos estimados para a tensão diferencial são resultantes da combinação entre os processos rúpteis e dúcteis registrados ao longo do espectro deformacional rúptil-dúctil da 
estrutura.

A ZCPE apresenta um particionamento heterogêneo da deformação. Os grãos de quartzo foram recristalizados no estado sólido e segregados em bandas monominerálicas a partir do mecanismo de recristalização rotacional de subgrãos. O feldspato, por sua vez, encontra-se deformado essencialmente por fraturamento associado à fluência difusiva e dissoluçãoprecipitação na presença de fluidos.

As estimativas de tensão diferencial realizadas nos domínios Caruaru e Gravatá exibem uma variação contínua e correspondem ao grau de recristalização dos agregados de quartzo. A diminuição dos valores de tensão diferencial próximos aos limites entres os domínios indica que há uma transição estrutural e reológica entre eles, a qual pode estar associada com a transformação dos milonitos do domínio Caruaru em ultramilonitos bandados no domínio Gravatá. As diferenças texturais e a retrogressão metamórfica envolvidos neste processo podem resultar em tamanhos de grão heterogêneos que refletem, ultimamente, o caráter heterogêneo da distribuição da deformação rúptil-dúctil no interior da ZCPE.

Os resultados paleopiezométricos de tensão diferencial ressaltam a eficiência da recristalização dinâmica como um mecanismo de localização e subsequente particionamento da deformação dúctil ao longo da ZCPE. A combinação entre fluência de deslocações em cristais de quartzo, fraturamento e dissoluçãoprecipitação em cristais de feldspato resulta no caráter transicional rúptil-dúctil observado na zona de cisalhamento Pernambuco. Tais condições, típicas de estruturas exumadas em níveis crustais intermediários a rasos, evidenciam a importância do fluxo no estado sólido para a acomodação da deformação em contextos metamórficos assistidos por fluidos.

Agradecimentos. Raylline Silva e Gustavo Viegas agradecem o apoio financeiro da FAPDF (Processo no 0193.001510/2017) e FAPESP (Processon 14/01114-2). Raylline Silva agradece o apoio da FAPDF através da concessão de bolsa de iniciação científica. Agradecimentos ao Paulo Castellan por leituras e comentários preliminares que contribuíram para o desenvolvimento do trabalho. Os autores são imensamente gratos às revisões detalhadas e construtivas dos revisores, e ao trabalho cuidadoso do Editor Cesar Schultz. Este trabalho é uma contribuição do grupo de pesquisa "Tectônica e fluxo de fluidos", certificado pelo CNPq.

\section{Referências}

Archanjo, C.J., Hollanda, M.H., Rodrigues, S.W., Neves, B.B. \& Armstrong, R. 2008. Fabrics of pre- and syntectonic granite plutons and chronology of shear zones in the Eastern Borborema Province, NE Brazil. Journal of Structure Geology, 30(3): 310-326.

Archanjo, C.J., Viegas, L.G., Hollanda, M.H., Souza, L.C. \& Liu, D. 2013. Timing of the HT/ LP transpression in the Neoproterozoic Seridó Belt (Borborema Province, Brazil): Constraints from U-Pb (SHRIMP) geochronology and implications for the connections between NE Brazil and West Africa. Gondwana Research, 23(2): 701-714

Brito Neves, B.B., Campos Neto, M.C. \& Fuck, R.A. 1999. From Rodinia to Western Gondwana: An approach to the Brasiliano-Pan African Cycle and orogenic collage. Episodes, 22(3): 155166.

Bukovská, Z., Jeřábek, P. \& Morales, L.F. 2016. Major softening at brittle-ductile transition due to interplay between chemical and deformation processes: An insight from evolution of shear bands in the South Armorican Shear Zone. Journal of Geophysical Research: Solid Earth, 121(2): 1158-1182.

Castellan, P., Viegas, G. \& Faleiros, F.M. 2020. Brittle-ductile fabrics and P-T conditions of deformation in the East Pernambuco shear zone (Borborema Province, NE Brazil). Journal of the Geological Society, 178(1): jgs2020-109.

Davison, I. \& Mccarthy, M. 1995. Laminar flow in shear zones: the Pernambuco Shear Zone, NEBrazil. Journal of Structural Geology, 17(2): 149-161.

Fitz Gerald, J.D. \& Stünitz, H. 1993. Deformation of granitoids at low metamorphic grade. I: Reactions and grain size reduction. Tectonophysics, 221(3/4): 269-297. 
Fitz Gerald, J.D., Mancktelow, N.S., Pennacchioni, G. \& Kunze, K. 2006. Ultrafine-grained quartz mylonites from high-grade shear zones: Evidence for strong dry middle to lower crust. Geology, 34(5): 369-372.

Fliervoet, T.F., White, S.H. \& Drury, M.R. 1997. Evidence for dominant grain-boundary sliding deformation in greenschist- and amphibolitegrade polymineralic ultramylonites from the Redbank Deformed Zone, Central Australia. Journal of Structural Geology, 19(12): 14951520.

Fossen, H. \& Cavalcante, G.C. 2017. Shear zones - A review. Earth-Science Reviews, 171: 434455.

Handy, M.R., Hirth, G. \& Bürgmann, R. 2007. Continental fault structure and rheology from the frictional-to-viscous transition downward. In: Handy, M.R., Hirth, G. \& Hovius, N. (Ed.) Tectonics Faults: agents of change on dynamic earth. Berlin, Dahlem Workshop Reports, p. 139-181.

Heilbronner, R. \& Barrett, S. 2014. Image Analysis in Earth Sciences. Berlin, Springer-Verlag, 520p.

Herwegh, M., Linckens, J., Ebert, A., Berger, A. \& Brodhag, S.H. 2011. The role of second phase for controlling microstructural evolution in polymineralic rocks: A review. Journal of Structural Geology, 33(12): 1728-1750.

Hirth, G. \& Tullis, J. 1992. Dislocation creep regimes in quartz aggregates. Journal of Structural Geology, 14(2): 145-159.

Ishii, K., Kanaguawa K., Shigesmatsu, N. \& Okudaira, T. 2007. High ductility of K-feldspar and development of granitic banded ultramylonite in the Ryoke metamorphic belt, SW Japan. Journal of Structural Geology, 29(6): 1083-1098.

Kilian, R., Heilbronner, R. \& Stünitz, H. 2011. Quartz grain size reduction in a granitoid rock and the transition from dislocation to diffusion creep. Journal of Structural Geology, 33(8): 1265-1284.

Lopez-Sanchez, M.A. \& Lhana-Fúnez, S. 2015. An evaluation of different measure of dynamically recrystallized grain size for paleopiezometry or paleowattometry studies. Solid Earth, 6: 475-495.
Menegon, L., Pennacchioni, G. \& Stünitz, H. 2006. Nucleation and growth of myrmekite during ductile shear deformation in metagranites. Journal of Metamorphic Geology, 24(7): 553568.

Menegon, L., Stünitz, H., Nasipuri, P., Heilbronner, R. \& Svahnberg, H. 2013. Transition from fracturing to viscous flow in granulite facies perthitic feldspar (Lofoten, Norway). Journal of Structural Geology, 48: 95-112.

Neves, S.P. \& Mariano, G. 1999. Assessing the tectonic significance of a large-scale transcurrent shear zone system: the Pernambuco lineament, northeastern Brazil. Journal of Structural Geology, 21(10): 13691383

Okudaira, T., Jeřábek, P., Stünitz, H. \& Fusseis, F. 2015. High-temperature fracturing and subsequent grain-size-sensitive creep in lower crustal gabbros: Evidence for coseismic loading followed by creep during decay stress in the lower crust? Journal of Geophysical Research: Solid Earth, 120(5): 3119-3141.

Okudaira, T., Shigematsu, N., Harigane, Y. \& Yoshida, K. 2017. Grain size reduction due to fracturing and subsequent grain-sizesensitive creep in a lower crustal shear zone in the presence of a CO2-bearing fluid. Journal of Structural Geology, 95: 171-187.

Park, Y., Yoo, S.-H. \& Ree, J.H. 2006. Weakening of deforming granitic rocks with layer development in the middle crust, Journal of Structure Geology, 28(5): 919-928.

Platt, J.P. 2015. Rheology of two-phase systems: a microphysical and observational approach. Journal of Structural Geology, 77: 213-227.

Stipp, M., Stünitz, H., Heilbronner, R. \& Schmid, S.M. 2002 The eastern Tonale fault zone: a 'natural laboratory' for crystal plastic deformation of quartz over a temperature range from 250 to $700^{\circ} \mathrm{C}$. Journal of Structural Geology, 24(12): 1861-1884.

Stipp, M. \& Tullis, J. 2003. The recrystallized grain size piezometer for quartz. Geophysical Research Letters, 30(21): 2088.

Tullis, J. 2002. Deformation of granitic rocks: experimental studies and natural examples. Reviews in Mineralogy and Geochemistry, 51(1): 51-95. 
Van Schmus, W.R., Brito Neves, B.B., Hackspacher, P.C. \& Babinski, M. 1995. U/Pb and Sm/ $\mathrm{Nd}$ geochronologic studies of the eastern Borborema Province, Northeast Brazil: initial conclusions. Journal of South America Earth Sciences, 8(3/4): 267-288.

Van Schmus, W.R., Oliveira, E.P. Silva Filho, A.F.D., Toteu, S.F., Penaye, J. \& Guimarães, I.P. 2008. Proterozoic links between the Borborema Province, NE Brazil, and the Central African Fold Belt. Journal of the Geological Society, 294(1): 69-99.

Vauchez, A. \& Egydio da Silva, M. 1992. Termination of a continental-scale strikeslip fault in partially melted crust: The West Pernambuco shear zone, northeast Brazil. Geology, 20(11): 1007-1010.

Vauchez, A., Neves, S.P., Caby, R., Corsini, M., Egydio-Silva, M., Arthaud, M. \& Amaro, V. 1995. The Borborema shear zone system, NE Brazil. Journal of South American Earth Sciences, 8(3/4): 247-266.

Viegas, L.G., Archanjo, C.J. \& Vauchez, A. 2013. Fabrics of migmatites and the relationships between partial melting and deformation in high-grade transpressional shear zones: the Espinho Branco anatexite (Borborema Province, NE Brazil). Journal of Structural
Geology, 48: 45-56.

Viegas, L.G., Archanjo, C.J., Hollanda, M. H. \& Vauchez, A. 2014. Microfabrics and zircon U$\mathrm{Pb}$ (SHRIMP) chronology of mylonites from the Patos shear zone (Borborema Province, NE Brazil). Precambrian Research, 243: 1-17.

Viegas, G., Menegon, L. \& Archanjo, C. 2016. Brittle grain-size reduction of feldspar, phase mixing and strain localization in granitoids at mid-crustal conditions (Pernambuco shear zone, NE Brazil). Solid Earth, 7: 375-396.

Warren, J.M. \& Hirth, G. 2006. Grain size sensitive deformation mechanisms in naturally deformed peridotites. Earth and Planetary Science Letters, 248(1/2): 438-450.

Wintsch, R.P. \& Yi, K. 2002. Dissolution and replacement creep: a significant deformation mechanism in mid-crustal rocks. Journal of Structural Geology, 24(6/7): 1179-1193. 